\title{
Exploring psychosocial predictors of STI testing in University students
}

\author{
H. A. Martin-Smith ${ }^{1 *}$ D. E. A. Okpo ${ }^{1}$ and E. R. Bull ${ }^{2}$
}

\begin{abstract}
Background: To explore university students' Sexually Transmitted Infection (STI) testing knowledge, psychosocial and demographic predictors of past STI testing behaviour, intentions to have an STI test, and high risk sexual behaviour, to inform interventions promoting STI testing in this population.

Methods: A cross-sectional, quantitative online survey was conducted in March 2016, recruiting university students from North East Scotland via an all-student email. The anonymous questionnaire assessed student demographics (e.g. sex, ethnicity, age), STI testing behaviours, sexual risk behaviours, knowledge and five psychological constructs thought to be predictive of STI testing from theory and past research: attitudes, perceived susceptibility to STIs, social norms, social fear and self-efficacy.

Results: The sample contained 1294 sexually active students (response rate 10\%) aged 18-63, mean age = 23.61 (SD 6.39), 888 (69\%) were female. Amongst participants, knowledge of STIs and testing was relatively high, and students held generally favourable attitudes. 52\% reported ever having an STI test, 13\% intended to have one in the next month; $16 \%$ reported unprotected sex with more than one 'casual' partner in the last six months. Being female, older, a postgraduate, longer UK residence, STI knowledge, perceived susceptibility, subjective norms, attitudes and self-efficacy all positively predicted past STI testing behaviour $(p<0.01)$. Perceived susceptibility to STIs and social norms positively predicted intentions to have an STI test in the next month $(p<0.05)$; perceived susceptibility also predicted past high-risk sexual behaviour $(p<0.01)$.
\end{abstract}

Conclusions: Several psychosocial predictors of past STI testing, of high-risk sexual behaviour and future STI intentions were identified. Health promotion STI testing interventions could focus on male students and target knowledge, attitude change, and increasing perceived susceptibility to STIs, social norms and self-efficacy towards STI-testing.

Keywords: Sexual health, Students, Health promotion, Sexually transmitted infections, Testing, Psychosocial determinants

\section{Background}

Sexually Transmitted Infections (STIs) are a significant public health problem. In England there were nearly half a million new diagnoses of STIs in 2015 alone [1]. If not treated, STIs can lead to serious long-term health sequelae such as pelvic inflammatory disease and infertility [1]. The impact of STIs is greatest in young people under 25 years old [1], including university students, who, are most likely to be exposed to key risk factors such as multiple sexual partners and unprotected sexual intercourse [2]. When used correctly and consistently, condoms are the most effective means of preventing an STI. Prompt testing, early

\footnotetext{
* Correspondence: hollymartinsmith3@gmail.com

${ }^{1} \mathrm{NHS}$ Grampian, Public Health Directorate, Aberdeen, UK

Full list of author information is available at the end of the article
}

diagnosis and treatment of STIs can reduce the incidence and complications associated with the disease by reducing onward transmission of infection to sexual contacts [3, 4].

Proactive approaches to STI testing tend to use population registers to invite individuals from a target population for screening; in opportunistic approaches individuals are offered testing whilst attending health services for other reasons [5]. Some European countries have national STI testing programmes, however uptake rates are generally low [6]. Results from a recent large survey in the UK [7] suggested that although rates of chlamydia testing in young adults aged 16-25 are increasing [8], the level still falls below the $35 \%$ of population needed to reduce prevalence of STIs [9]. Many young people are not attending

(c) The Author(s). 2018 Open Access This article is distributed under the terms of the Creative Commons Attribution 4.0 International License (http://creativecommons.org/licenses/by/4.0/), which permits unrestricted use, distribution, and reproduction in any medium, provided you give appropriate credit to the original author(s) and the source, provide a link to the Creative Commons license, and indicate if changes were made. The Creative Commons Public Domain Dedication waiver (http://creativecommons.org/publicdomain/zero/1.0/) applies to the data made available in this article, unless otherwise stated. 
STI testing services and so effective efforts to encourage testing uptake are required.

To date a limited number of studies have explored the psychosocial determinants of STI testing in a university setting. Traditional STI research has shown that STI testing rates can vary substantially according to age, gender, ethnicity, education level as well as STI-related knowledge and systemic factors [10]. More recent research has explored more complex social and psychological factors such as perceived norms and perceived susceptibility informed by health psychology theories [11-13] and found these to be significant predictors of behaviour.

Indeed, according to the Theory of Planned Behaviour [14] a person's behaviour depends on their 'behavioural beliefs', or attitudes, relating to possible outcomes of the behaviour, their 'normative beliefs' about significant others' expectations about their behaviour, which can create perceived social pressure (subjective norms) and 'control beliefs' about the power of barriers to performing the behaviour, which creates perceived behavioural control. Positive attitudes, subjective norms and perceived behavioural control lead to stronger intention and thus likelihood of behaviour change. This theory has been applied to explain sexual behaviours such as condom use [15] and more recently in understanding barriers to STI testing [12]. Later versions of the model and meta-analyses also acknowledge the additive effect of descriptive norms, or individuals' beliefs about what others' do, which may be especially important for younger populations and for health risk behaviours $[16,17]$.

The Health Belief Model [18] proposed alternative constructs including perceived susceptibility or vulnerability to a condition (such as an STI), perceived severity if it occurred, perceived benefits of taking preventative action (e.g. STI testing) and beliefs about barriers to this action. This model has also been applied to explain condom use [19] and only recently to understanding the factors impacting a person's decision to take an STI test [12].

Social Cognitive Theory [20] emphasises self-efficacy (one's confidence to perform behaviour) in determining which behaviour a person chooses to perform, their persistence in the face of obstacles and how well they will perform that behaviour. Increased self-efficacy is also thought to be one mediator of the link between descriptive norms and behaviour, the idea that if similar people to me do X, then I must be able to do it too' [21]. The role of self-efficacy has been applied to explain the initiation and maintenance of many health behaviours including alcohol consumption [22]; physical activity [23], and many others; again infrequently in STI testing [12].

In addition social factors (such as social fear based on sociological research of stigma and fear of negative consequences) has been identified to impact on a young persons decision to have an STI test from qualitative and quantitative research [12, 24].

Application of these theories and sociological factors in exploring STI testing behaviours have resulted in somewhat inconsistent and fragmented findings [11-13]. Furthermore, sexual health promotion interventions and communications are not always based on careful analysis of the evidence around predictors of behaviour: one study of safer sex leaflets found most messages targeted knowledge about condoms rather than information about perceived attitudes even though the latter was more strongly correlated with actual condom use [25].

Building on this evidence is important to gain a further understanding of social and psychological factors influencing STI testing behaviour, particularly to inform practice for those working in settings with high proportions of under 25 year olds, such as universities. The objectives of this study were to:

1) Explore university students' STI testing knowledge, psychosocial and demographic factors and behaviours.

2) Understand which psychosocial and demographic factors predict STI testing, intentions and sexual risk behaviour.

Ultimately, this aimed to inform effective interventions for promoting STI testing in university students.

\section{Methods \\ Design}

A quantitative cross-sectional survey study using an anonymous, self-administered online survey developed following a review of the literature. The questionnaire was developed systematically using theory-based psychological constructs found to be predictive of behaviour in previous research, and where possible, using validated measures and scores (see Additional file 1 for further detail on definitions and measures and Additional file 2 for the full questionnaire). Questions assessed students' sexual health behaviours, intentions to attend an STI test in the next month, demographic characteristics (age, sex, ethnic background, year of study and number of years living in the UK), STI knowledge and the five theory-based psychosocial constructs (perceived susceptibility, social norms, attitudes, social fear and self-efficacy). The questionnaire was piloted with a convenience sample of seven health psychology researchers and students and minor amendments were made. The main behavioural outcome variables were STI testing history (ever), intentions to attend an STI test in the next month and sexual risk behaviour (defined in this study as unprotected (no condom) sex with two or more sexual partners in the last six months). 


\section{Setting}

This study was conducted among students in a North East Scotland University in March 2016.

\section{Participants}

Eligible participants were all sexually active registered undergraduate and postgraduate students in all faculties in a North East Scotland University in March 2016 (16,435 students).

Participants were invited to complete the survey via an email that was sent to all the students from the university with a link to the online survey questionnaire. Participation was voluntary, anonymous and required online consent. Students were introduced to the topic and advised of the voluntary and anonymous nature of the study, their right to withdraw, and to researcher contact details. An opt-in checkbox indicated participants' informed consent. Only participants who indicated that they had ever been sexually active were included in the final analysis. The survey was live for two weeks, during which time two reminder emails were sent to facilitate recruitment.

\section{Statistical analyses}

The submitted anonymous surveys were coded numerically, scores for individual items were summed into composite scores based on previous research (full details of data treatment can be found in Additional file 1), and analysis was performed using SPSS (version 20.0).

To further explore sample characteristics in relation to population characteristics, we examined differences between our sample with the university student population, using demographic data on ethnicity, age and sex from the University records office, using Chi-square tests.

Data were assessed for normal distribution using Shapiro-Wilk test of normality. Where data were not normally distributed, the median and interquartile range (IQR) was reported. Chi-square tests and Mann Whitney U tests examined differences, means ranks were investigated when differently shaped distributions of the independent variable occurred. Odds Ratios (OR) with associated 95\% confidence intervals $(95 \% \mathrm{CI})$ were used to measure the association between two attributes. Logistic regression models were then used to assess which psychosocial (including knowledge and demographic) factors predicted past STI testing, sexual risk behaviour and intentions to attend STI testing in the next month. Cronbach's alpha was used to assess the internal consistency of items within each construct of psychosocial measures, with $>.07$ taken as adequate consistency. Cronbach alpha coefficients were all above 0.7 except for the descriptive norms scale $[\alpha=.59]$. There was poor inter-item correlation between the three question items $(r=0.11-0.52)$ making up this scale and little improvement in Cronbach's alpha with the deletion of any item, so for parsimony descriptive norms was removed from the analysis.

\section{Results \\ Participants}

A total of 1600 students participated (response rate 10\%), 297 were excluded due to sexually inactivity and 9 were excluded owing to not completing over $50 \%$ of the survey. The final analyses were performed on 1294 individuals. Of these, 69\% (888/1294) were female and the mean age was 23.68 years (standard deviation, SD 6.44, range 18-63). The response rate was higher for female undergraduates from a white ethnic background compared to official university records on the overall female student population. Table 1 shows the characteristics of study participants.

\section{Objective 1: Student knowledge, psychosocial and demographic factors surrounding STI testing}

Knowledge of STIs/STI-testing In the 14-item (true/ false) STI/STI-Testing knowledge section, the median number of correctly answered questions was 10.0 (IQR 9.0-12.0). Male students (median $=11.0, \mathrm{IQR}=8.0-13.0$ had greater STI/STI-Testing knowledge than female students (median $=10.0, \mathrm{IQR}=9.0-12.0$ ) however this was not found to be a statistically significant difference $(\mathrm{U}=174,242.5, \mathrm{z}=-.619, p=.53)$. Similarly white students (median $=11.0, \mathrm{IQR}=9.0-12.0)$, students who had lived in the UK more than 5 years $($ median $=11.0, \mathrm{IQR}=9.0-11.0$ ) and undergraduate students (median $=11.0, \quad \mathrm{IQR}=$ 9.0-12.0) had greater STI/STI-Testing knowledge than non-white students (median $=9.0, \mathrm{IQR}=6.0-12.0$ ), students who had lived in the UK $0-5$ years (median $=9.0$, $\mathrm{IQR}=7.0-11.0$ ) and postgraduate students (median = 10.0 , IQR $=7.0-12.0$ ), and these differences were found to be statistically significant $(p<.001)$.

Psychosocial factors surrounding STIs and STI testing Overall, participant direct and indirect attitudes were favourable towards STI testing (Median $=31.0, \mathrm{IQR}=$ 28.0 -32.0 and Median $=42.0$, IQR $=39.0-46.0$ respectively). In terms of the other psychosocial variables, social fear towards STI testing and perceptions of susceptibility to an STI were low (Median $=16.0, \mathrm{IQR}=10.0-24.0$ ) and (Median $=4.0, \mathrm{IQR}=4.0-5.0$ ) respectively. Perception of social pressure (subjective norms) and confidence (self-efficacy) to attend an STI test were moderate $($ Median $=4.0, \mathrm{IQR}=-15.0-20.0)$ and $($ Median $=38.0$, $\mathrm{IQR}=31.0-47.0$ 15.0) respectively. The median score for descriptive norms towards STI testing was moderate (Median =8.0, IQR =6.0-9.0). Table 1 includes median and interquartile ranges for participants' scores on the psychosocial variables. 


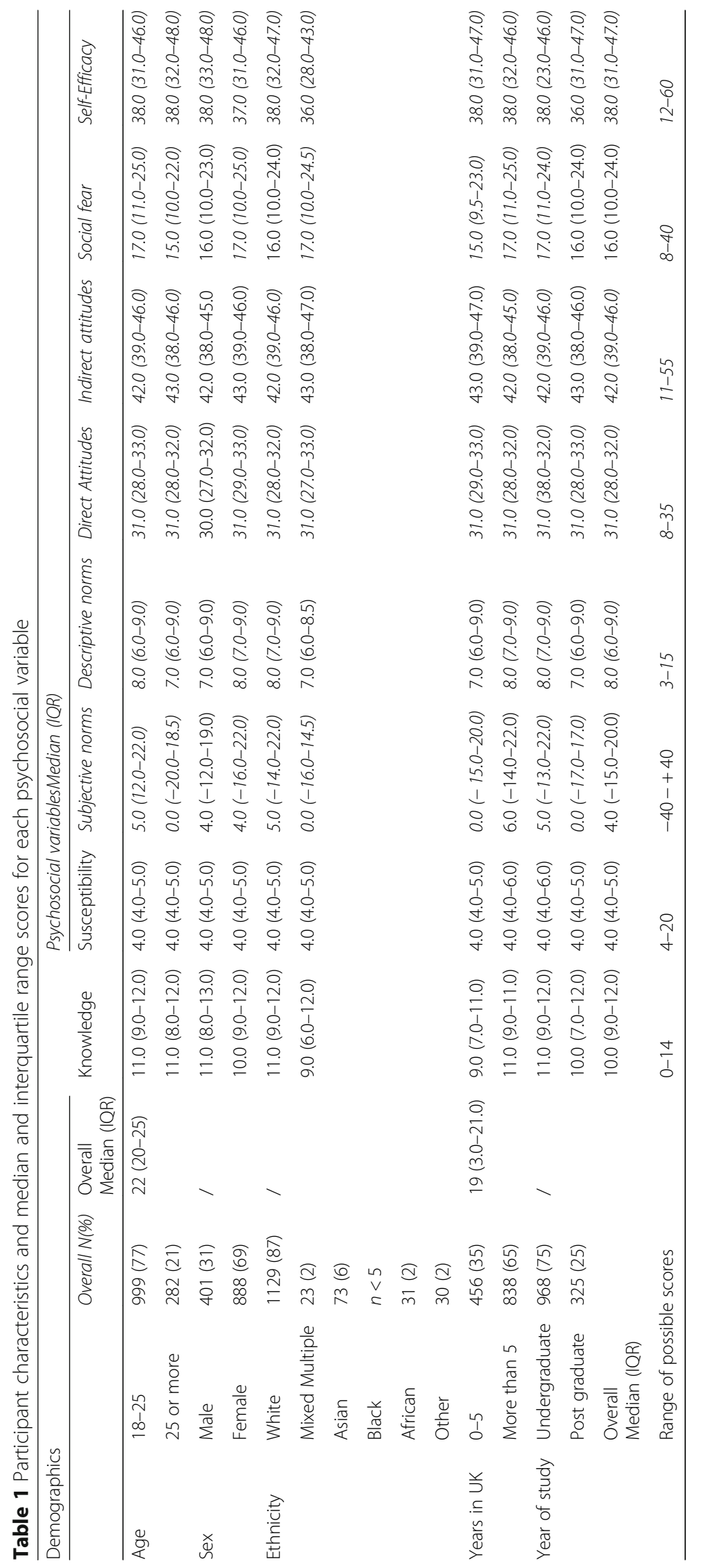


Behaviour Fifty two percent (678) of students who completed the survey reported having ever had an STI test, 20.5\% (266) reported having had an STI test in the last six months, $13 \%$ (166) indicated an intention to attend an STI test in the next month and 16\% (181) reported unprotected sex with more than one casual partner in last six months.

\section{Objective 2: Psychosocial factors predicting university students' past STI testing behaviours, intentions to attend an STI test and sexual risk behaviours}

Past STI testing Results of regression analysis showed that females and students aged 25 or over, postgraduates and students who had been in the UK for more than 5 years were more likely to have had an STI test in the past. Similarly knowledge, perceived susceptibility, subjective norms, direct and indirect attitudes and self-efficacy were all predictors of past STI testing behaviour. High scores on these variables meant students were more likely to have had an STI test in the past (Table 2).

Intentions to go for an STI test Furthermore, ethnicity, perceived susceptibility and social norms predicted intentions to get tested in the next month with white students being less likely to express an intention to get an STI than those of other ethnicities, and high perceived susceptibility and subjective norms meaning students were more likely to express intention to get tested (Table 3).
Sexual behaviour Table 4 below shows that socio-demographic variables had no statistically significant effect on high risk sexual behaviour in the past six months, defined as having had unprotected (no condom) sex with multiple sexual partners (two or more) in the last six months. Perceived susceptibility and subjective norms were the only predictors of past risky behaviour. For every one-unit increase in susceptibility and subjective norms score, students were 33 and $1 \%$ more likely to have engaged in risky behaviour in the past, respectively.

\section{Discussion}

This study assessed knowledge, psychosocial and demographic factors and behaviours surrounding STI testing and explored theoretically-relevant psychosocial predictors of past STI testing, intentions to attend an STI test and high risk sexual behaviour in a student population in Scotland, United Kingdom.

Participants had a relatively high level of knowledge of STIs and STI testing and younger students (18-25 years), undergraduate and students who have lived in the UK for over 5 years statistically significantly answered more knowledge questions correctly.

Approximately half of participants reported ever attending an STI test, similar to the proportion of women reporting having had a chlamydia test in the national survey [7]. Similar to other studies, women and students over 25 years old were more likely to report having been tested for STIs [12], confirming that under $25 \mathrm{~s}$ may

Table 2 Results of logistic regression of past STI testing behaviour $(n=1212)$

\begin{tabular}{|c|c|c|c|c|c|}
\hline & Variable & & Odds ratio & $95 \% \mathrm{Cl}$ & $p$ value \\
\hline \multirow[t]{10}{*}{ Demographics } & Age & $18-25$ & Reference & & \\
\hline & & 25 or more & 1.522 & $1.019-2.273$ & $p=.040$ \\
\hline & Sex & Male & Reference & & \\
\hline & & Female & 2.134 & $1.599-2.847$ & $p<.001$ \\
\hline & Ethnicity & Non White & Reference & & \\
\hline & & White & 1.107 & $0.718-1.796$ & $p=.645$ \\
\hline & Number of years in UK & $0-5$ & Reference & & \\
\hline & & More than 5 & 0.706 & $0.521-0.957$ & $p=.025$ \\
\hline & Year of study & Undergraduate & Reference & & \\
\hline & & Post graduate & 1.551 & $1.053-2.285$ & $p=.026$ \\
\hline \multirow[t]{8}{*}{ Psychosocial } & Knowledge & & 1.254 & $1.185-1.326$ & $p<.001$ \\
\hline & Susceptibility & & 1.076 & $1.022-1.134$ & $p=.006$ \\
\hline & Subjective norms & & 1.014 & $1.008-1.020$ & $p<.001$ \\
\hline & Direct attitudes & & 1.037 & $1.000-1.075$ & $p=.048$ \\
\hline & Indirect attitudes & & 1.063 & $1.030-1.097$ & $p<.001$ \\
\hline & Social Fear & & 1.000 & $0.982-1.018$ & $p=.972$ \\
\hline & Self-Efficacy & & 1.042 & $1.027-1.057$ & $p<.001$ \\
\hline & Intention & & 1.027 & $0.667-1.581$ & $P=.901$ \\
\hline
\end{tabular}


Table 3 Results of logistic regression of intentions to have an STI test in the next month $(n=1212)$

\begin{tabular}{|c|c|c|c|c|c|}
\hline & Variable & & Odds ratio & $95 \% \mathrm{Cl}$ & $p$ value \\
\hline \multirow[t]{10}{*}{ Demographics } & Age & $18-25$ & Reference & & \\
\hline & & 25 or more & 1.446 & $0.825-2.536$ & $p=.198$ \\
\hline & Gender & Male & Reference & & \\
\hline & & Female & 0.889 & $0.590-1.340$ & $p=.575$ \\
\hline & Ethnicity & Non White & Reference & & \\
\hline & & White & 0.425 & $0.246-0.735$ & $p=.002$ \\
\hline & Number of years in UK & $0-5$ & Reference & & \\
\hline & & More than 5 & 0.913 & $0.588-1.417$ & $p=.685$ \\
\hline & Year of study & Undergraduate & Reference & & \\
\hline & & Post graduate & 0.637 & $0.355-1.141$ & $p=.129$ \\
\hline \multirow[t]{8}{*}{ Psychosocial } & Knowledge & & 1.005 & $0.927-1.090$ & $p=.901$ \\
\hline & Susceptibility & & 1.236 & $1.174-1.300$ & $p<.001$ \\
\hline & Subjective norms & & 1.024 & $1.015-1.034$ & $p<.001$ \\
\hline & Direct attitudes & & 1.052 & $0.990-1.118$ & $p=.100$ \\
\hline & Indirect attitudes & & 1.030 & $0.985-1.078$ & $p=.194$ \\
\hline & Social Fear & & 1.002 & $0.976-1.030$ & $p=.869$ \\
\hline & Self-Efficacy & & 1.007 & $0.987-1.028$ & $p=.484$ \\
\hline & Past STI testing & & 1.078 & $0.696-1.670$ & $p=.735$ \\
\hline
\end{tabular}

indeed be a 'high-risk' group. Women over 25 in particular may generally have more opportunity for STI testing given cervical screening and other contact with health care providers for reproductive health issues. Postgraduates and students who had lived in the UK for more than 5 years were also more likely to have had an STI test.
Our study showed that knowledge was also a predictor of past STI testing behaviour. Similar findings have been reported by some studies [26, 27]. In contrast to one study in Australia [12] that reported no link between knowledge of STI and risk behaviour. A growing consensus suggests that increasing knowledge is necessary but

Table 4 Results of logistic regression of sexual risk behaviour i.e. Unprotected (no condom) and multiple sexual partners (2 or more) in the last 6 months $(n=1104)$

\begin{tabular}{|c|c|c|c|c|c|}
\hline & Variable & & Odds ratio & $95 \% \mathrm{Cl}$ & $p$ value \\
\hline \multirow[t]{10}{*}{ Demographics } & Age & $18-25$ & Reference & & \\
\hline & & 25 or more & 0.656 & $0.355-1.212$ & $p=.178$ \\
\hline & Sex & Male & Reference & & \\
\hline & & Female & 0.854 & $0.574-1.269$ & $p=.434$ \\
\hline & Ethnicity & Non White & Reference & & \\
\hline & & White & 0.579 & $0.324-1.034$ & $p=.065$ \\
\hline & Number of years in UK & $0-5$ & Reference & & \\
\hline & & More than 5 & 1.243 & $0.801-1.930$ & $p=.333$ \\
\hline & Year of study & Undergraduate & Reference & & \\
\hline & & Post graduate & 0.591 & $0.325-1.073$ & $p=.084$ \\
\hline \multirow[t]{7}{*}{ Psychosocial } & Knowledge & & 1.044 & $0.965-1.130$ & $p=.284$ \\
\hline & Susceptibility & & 1.331 & $1.258-1.408$ & $p<.001$ \\
\hline & Subjective norms & & 1.011 & $1.002-1.019$ & $p=.018$ \\
\hline & Direct attitudes & & 1.001 & $0.950-1.054$ & $p=.974$ \\
\hline & Indirect attitudes & & 1.009 & $0.966-1.054$ & $p=.684$ \\
\hline & Social Fear & & 1.012 & $0.987-1.039$ & $p=.348$ \\
\hline & Self-Efficacy & & 1.007 & $0.987-1.028$ & $p=.488$ \\
\hline
\end{tabular}


not sufficient for behaviour change, given other complex factors that contribute to health-seeking behaviour (e.g. self-efficacy, social norms and socio-structural factors) [28]. Other less strongly positive associated predictors of STI testing included high perceptions of susceptibility, high social pressure (subjective norms) to attend STI testing, with favourable direct and indirect attitudes and high confidence to attend a test. These findings are inconsistent with previous studies, perhaps due to differences in methodology and culture. It emphasises the complex nature of sexual health behaviours such as STI testing cementing the need for diverse initiatives to tackle this public health problem.

Few students intended to attend an STI test in the next month (13\%). Similar to other studies, intention to participate in STI testing among students in this population was driven by perceived susceptibility and subjective norms [11-13] and multiple partners [29] however other research $[30,31]$ identified variables such as perceived behavioural control, self-identity, motivation and cues to action as important predictors of intentions. This highlights the possible need to further explore intentions within this population including variables not assessed in the survey.

A small number of students reported engagement in sexual risk behaviour in the past (16\%).

The finding that high scores of susceptibility for an STI and social pressure to attend an STI test meant students were more likely to have engaged in past risky behaviour is important. It suggests students accurately judged themselves to be susceptible, whilst feeling social pressure to attend an STI test if they'd taken a risk. In comparison previous reviews, explored determinants of sexual risk behaviour, but with inconsistent results. Some identified attitudes, behavioural intentions and behavioural skills as correlates of sexual behaviours [32]. The majority of this research was based on correlation data from cross-sectional studies which is limited as temporality is unable to be established. In light of the above, current theoretical models of sexual risk behaviour warrant further investigation and possible adaptation.

Since a range of psychosocial and demographic factors were associated with STI testing, sexual health promotion interventions could benefit from targeting specific student groups and by addressing relevant psychosocial factors. Some recommendations that interventions may address in their design are as follows 1) promote and strengthen positive norms around testing to build on health promotion, 2) address young people's perceptions of personal risk of contracting an STI, 3) promote and strengthen positive attitudes towards STI testing, 4) increase confidence to attend STI testing. There are several practical intervention ideas based on previous research that could be applied to focus on these key psychosocial factors to increase uptake of STI testing. Firstly marketing campaigns that deliver health messages have been found to positively impact on changing health behaviours [33]. Peer-led screening uses peer education to promote positive social norms and positive attitudes through modelling and normalising [34]. A role-modelling intervention could involve displaying video messages around campuses with students sharing their experiences of going for an STI test to increase self-efficacy and finally utilising social networks within universities by recruiting advocates who could spread behaviour change recommendations to their peers. Furthermore since younger, undergraduate, male students were found to be less likely to have attended testing, it is feasible that these interventions could focus on this sub group of students to help encourage more young people to have an STI test.

Overall, this cross-sectional study contributes to the body of evidence on factors that impact STI testing behaviours and demonstrates the complexity of social and psychological factors that impact on STI testing behaviours; further research to validate the findings using a prospective longitudinal study is required.

\section{Strengths and limitations}

The current study is the first of its kind in this population in Scotland, adding to the limited body of evidence in this topic area. It is strengthened by the systematic development of the survey allowing for a wide range of factors to be assessed including demographic, behavioural and psychosocial factors regarding STI testing. Moreover this study attracted a relatively large sample size comparing favourably with other small-scale cross-sectional studies. However there are several limitations, not least that the cross-sectional design allows only for statistically significant associations between behaviour and their potential determinants. Cross-sectional surveys use self-reports of behaviour, risking recall and reporting bias. Participation bias may also have occurred if some people may be more willing than others to participate in this sensitive topic, and given the online nature of the survey although most if not all students would be likely to be able to access a computer. Like many other surveys, males aged 18-25 were under-represented, which could affect validity and generalizability of the findings. Ceiling and floor effects occurred when measuring some of the psychosocial variables, limiting the range of data reported leading to non-normally distributed data. Fortunately, the analytical test used in this study did not require normally distributed data, and as the sample size in this study was fairly large the negative effect of this response bias is reduced. The 10\% response rate was larger than the $7 \%$ reported in another university-based sexual health study [35]: other comparable online sexual health questionnaire studies have not tended to report response 
rates and yield smaller overall sample sizes [13, 36]. Our response rate was naturally smaller than the more representative UK-wide national survey The National Survey of Sexual Attitudes and Lifestyles [7], who are resourced to visit potential participants in their home and offer monetary incentives for participation. We were not able to assess the predictive effect of descriptive norms, despite this being a potentially important influence on young people's behaviour [17] as internal consistency was poor with low inter-item correlation. Further exploratory work would be useful to better understand which are the key referent groups for university students, if descriptive norms vary substantially. Nevertheless, this study adds to our understanding of several theory-based psychological factors associated with high-risk behaviours and STI testing in this important student population: further replication on a national scale would now be useful.

\section{Conclusions}

This study found several demographic and psychosocial factors influencing STI testing behaviour, high-risk sexual behaviour and future intentions towards STI testing. Perceptions of risks and social pressure are important factors in sexual risk behaviours in the past and intentions to attend an STI test in the future. STI testing interventions could target young, male students from outside the UK and aim to boost (increase) susceptibility (i.e. perceptions of vulnerability), social norms (i.e. perceptions of social pressure) and confidence to attend for testing. The results from this study provide a useful direction for further behavioural change research and health promotion intervention design.

\section{Additional files}

Additional file 1: Definitions and measurements. This file provides further detail on measures and scoring for the questionnaire constructs. (DOCX $16 \mathrm{~kb}$ )

Additional file 2: STI Screening Questionnaire. This file provides the full questionnaire used to survey participants. (DOCX $76 \mathrm{~kb}$ )

\section{Abbreviations}

Cl: Confidence Interval; IQR: Interquartile Range; OR: Odds Ratio; SD: Standard Deviation; STI: Sexually Transmitted Infection

\section{Acknowledgements}

We would like to acknowledge and thank the following individuals for their contribution to the success of this research Mr. Calvin Heel, University of Manchester Statistician, Dr. Neil Scott, University of Aberdeen Statistician, members of the Aberdeen Health Psychology Group at the University of Aberdeen, and the participants who responded to the survey.

\section{Availability of data and materials}

The original datasets used and/or analyzed during the current study are available from the corresponding author on reasonable request.

\section{Author's contributions}

HMS was involved in the conception and design of the work data collection, data analysis and interpretation, drafting the manuscript, revising the manuscript and final approval of the version to be published. EB and EO supervised the conception and design of the work, data analysis and interpretation, critical revision of the manuscript and final approval of the version to be published. All authors read and approved the final manuscript.

\section{Ethics and consent to participate}

Ethical approval for the study was granted by the College Ethics Review Board at the University of Aberdeen (ethical approval number: CERB/2015/ 11/1235). Consent to participate was obtained at the beginning of the online survey, participants read a description of the study before clicking a button to indicate their consent to participate.

\section{Competing interests}

The authors declare that they have no competing interests.

\section{Publisher's Note}

Springer Nature remains neutral with regard to jurisdictional claims in published maps and institutional affiliations.

\section{Author details}

${ }^{1} \mathrm{NHS}$ Grampian, Public Health Directorate, Aberdeen, UK. ${ }^{2}$ Division of Medical Education, School of Medical Sciences, Faculty of Biology, Medicine and Health, The University of Manchester, Manchester, UK.

Received: 17 November 2017 Accepted: 23 May 2018

Published online: 29 May 2018

\section{References}

1. Public Health England, Sex Transm Infect (STIs): annual data tables, (London: PHE, 2016) Accessed 06/10/2016 https://www.gov.uk/government/uploads/ system/uploads/attachment_data/file/559993/hpr2216_stis_CRRCTD4.pdf

2. Holmes KK, Levine R, Weaver M. Effectiveness of condoms in preventing sexually transmitted infections. Bull World Health Organ. 2004 Jun;82(6):454-61.

3. Marrazzo JM, Cates W. Interventions to prevent sexually transmitted infections, including HIV infection. Clin Infect Dis. 2011 Dec 15;53(suppl 3):S64-78.

4. Mayaud P, Mabey D. Approaches to the control of sexually transmitted infections in developing countries: old problems and modern challenges. Sex Transm Infect. 2004 Jun 1;80(3):174-82.

5. Low N, Bender N, Nartey L, Redmond S, Shang A, Stephenson J. Revised rapid review of evidence for the effectiveness of screening for genital chlamydial infection in sexually active young women and men. London: National Institute for Clinical Excellence; 2006.

6. van den Broek IV, van Bergen JE, Brouwers EE, Fennema JS, Götz HM, Hoebe CJ, Koekenbier RH, Kretzschmar M, Over EA, Schmid BV, Pars LL. Effectiveness of yearly, register based screening for chlamydia in the Netherlands: controlled trial with randomised stepped wedge implementation. BMJ. 2012 Jul 5;345:e4316.

7. Erens B, Phelps A, Clifton S, Mercer CH, Tanton C, Hussey D, Sonnenberg P, Macdowall W, Field N, Datta J, Mitchell K. Methodology of the third British National Survey of sexual attitudes and lifestyles (Natsal-3). Sex Transm Infect. 2013 Nov 25:sextrans-2013.

8. Woodhall SC, Soldan K, Sonnenberg P, Mercer CH, Clifton S, Saunders P, da Silva F, Alexander S, Wellings K, Tanton C, Field N. Is chlamydia screening and testing in Britain reaching young adults at risk of infection? Findings from the third National Survey of sexual attitudes and lifestyles (Natsal-3). Sex Transm Infect. 2016 May 1:92(3):218-27.

9. Normansell R, Drennan VM, Oakeshott P. Exploring access and attitudes to regular sexually transmitted infection screening: the views of young, multiethnic, inner-city, female students. Health Expect. 2016 Apr;19(2):322.

10. Lau A, Spark S, Tomnay J, Smith MT, Fairley CK, Guy RJ, Donovan B, Hocking JS. Socio-demographic and structural barriers to being tested for chlamydia in general practice. Med J Aust. 2016 Feb 15;204(3):112.

11. Wolfers ME, Kok G, Mackenbach JP, de Zwart O. Correlates of STI testing among vocational school students in the Netherlands. BMC Public Health 2010 Nov 24;10(1):725.

12. Hermans J, Story L, Edwards B, Murray C, Bourne C. Understanding barriers to STI testing among young people. Sydney, National Centre in HIV social research, The University of new South Wales; 2011. 
13. de Visser RO, O'Neill N. Identifying and understanding barriers to sexually transmissible infection testing among young people. Sex Health. 2013 Nov 18;10(6):553-8

14. Ajzen I. The theory of planned behavior. Organ Behav Hum Decis Process. 1991 Dec 1;50(2):179-211.

15. Albarracin D, Johnson BT, Fishbein M, Muellerleile PA. Theories of reasoned action and planned behavior as models of condom use: a meta-analysis. Psychol Bull. 2001 Jan;127(1):142.

16. Ajzen I, Fishbein M. The influence of attitudes on behaviour. In: Albarracín D, Johnson BT, Zanna MP, editors. The handbook of attitudes. Mahwah, NJ: Lawrence Erlbaum; 2005. p. 173-221.

17. Rivis A, Sheeran P. Descriptive norms as an additional predictor in the theory of planned behaviour: a meta-analysis. Curr Psychol. 2003 Sep 1; 22(3):218-33.

18. Conner M, Norman P. Predicting health behaviour. McGraw-Hill Education (UK); 2005 Jul 1.

19. Winfield EB, Whaley AL. A comprehensive test of the health belief model in the prediction of condom use among African American college students. J Black Psychology. 2002 Nov 1;28(4):330-46.

20. Bandura A. Self-efficacy in changing societies. UK: Cambridge university press; 1995.

21. Stok FM, Verkooijen KT, Ridder DT, Wit JB, Vet E. How norms work: selfidentification, attitude, and self-efficacy mediate the relation between descriptive social norms and vegetable intake. Appl Psychol Health Well Being. 2014 Jul 1:6(2):230-50.

22. Gilles DM, Turk CL, Fresco DM. Social anxiety, alcohol expectancies, and selfefficacy as predictors of heavy drinking in college students. Addict Behav. 2006 Mar 31;31(3):388-98.

23. Hammer NM, Bieler T, Beyer N, Midtgaard J. The impact of self-efficacy on physical activity maintenance in patients with hip osteoarthritis-a mixed methods study. Disabil Rehabil. 2016 Aug 13;38(17):1691-704.

24. Barth KR, Cook RL, Downs JS, Switzer GE, Fischhoff B. Social stigma and negative consequences: factors that influence college students' decisions to seek testing for sexually transmitted infections. J Am Coll Heal. 2002 Jan 1; 50(4):153-9.

25. Abraham C, Krahé B, Dominic R, Fritsche I. Does research into the social cognitive antecedents of action contribute to health promotion? A content analysis of safer-sex promotion leaflets. $\mathrm{Br} J$ Health Psychol. 2002;7:227-46.

26. Hocking JS, Parker RM, Pavlin N, Fairley CK, Gunn JM. What needs to change to increase chlamydia screening in general practice in Australia? The views of general practitioners. BMC Public Health. 2008 Dec 30;8(1):425.

27. Deblonde J, De Koker P, Hamers FF, Fontaine J, Luchters S, Temmerman M. Barriers to HIV testing in Europe: a systematic review. Eur J Pub Health. 2010 Aug 1;20(4):422-32

28. Lim MS, Hocking JS, Aitken CK, Fairley CK, Jordan L, Lewis JA, Hellard ME. Impact of text and email messaging on the sexual health of young people: a randomised controlled trial. J Epidemiol Community Health. 2012 Jan 1;66(1):69-74.

29. Gill A, Ruiter RA, van Bergen JE, Hoebe CJ, Dukers-Muijrers NH, Kok G. Predictors of chlamydia trachomatis testing: perceived norms, susceptibility, changes in partner status, and underestimation of own risk. BMC Public Health 2015 Dec;16(1):55.

30. Booth AR, Norman P, Harris PR, Goyder E. Using the theory of planned behaviour and self-identity to explain chlamydia testing intentions in young people living in deprived areas. Br J Health Psychol. 2014 Feb 1;19(1):101-12.

31. Westmaas AH, Kok G, Vriens P, Götz H, Richardus JH, Voeten $H$. Determinants of intention to get tested for STI/HIV among the Surinamese and Antilleans in the Netherlands: results of an online survey. BMC Public Health. 2012 Nov 9;12(1):961.

32. Kalichman SC, Picciano JF, Roffman RA. Motivation to reduce HIV risk behaviors in the context of the information, motivation and behavioral skills (IMB) model of HIV prevention. J Health Psychol. 2008 Jul;13(5): 680-9.

33. Sheeran P, Harris PR, Epton T. Does heightening risk appraisals change people's intentions and behavior? A meta-analysis of experimental studies. Psychol Bull. 2014 Mar;140(2):511.

34. Loaring J, Hickman M, Oliver I, Campbell R, Trotter C, Macleod J, Pye K, Crichton J, Horner P. Could a peer-led intervention increase uptake of chlamydia screening? A proof of principle pilot study. J Fam Plann Reprod Health Care. 2012 Aug;(1):familyplanning-2011.
35. Chanakira E, Goyder EC, Freeman JV, O'Cathain A, Kinghorn G, Jakubovic M. Social and psychosocial factors associated with high-risk sexual behaviour among university students in the United Kingdom: a web-survey. Int J STD AIDS. 2015 May;26(6):369-78.

36. Llewellyn CD, Sakal C, Lagarde M, Pollard A, Miners AH. Testing for sexually transmitted infections among students: a discrete choice experiment of service preferences. BMJ Open. 2013 Oct 1;3(10):e003240.

\section{Ready to submit your research? Choose BMC and benefit from:}

- fast, convenient online submission

- thorough peer review by experienced researchers in your field

- rapid publication on acceptance

- support for research data, including large and complex data types

- gold Open Access which fosters wider collaboration and increased citations

- maximum visibility for your research: over $100 \mathrm{M}$ website views per year

At BMC, research is always in progress.

Learn more biomedcentral.com/submissions 